\title{
POSSIBILIDADES DO MERCADO DE SERVIÇOS NO BRASIL
}

ALBERTO DE OLIVEIRA LIMA FILHO

"Em vez de pensar no passado e nos sinais de pompa e grandeza que se desvaneceram, a mente se regozija com as imagens do poder e esplendor que virão." - ChaRles Lyell

O conhecimento de uma economia em fase de desenvolvimento, como a brasileira, com seus desequilíbrios regionais e estruturais, leva o estudioso de Mercadologia a questionar a possibilidade de examinar sistemàticamente nosso mercado de serviços. No Brasil existem regióes - a amazônica e a centro-oeste, por exemplo — em que o desenvolvimento econômico não alcançou sequer o primeiro estágio; por outro lado, vêem-se regiões - como a do Sul - onde os problemas de produção foram quase totalmente solucionados. Em consequiência, o esfôrço mercadológico bem orientado torna-se aí fator de real importância.

Nas próprias regiões mais desenvolvidas, porém, a análise não deve ser realizada sem a introdução destas variáveis: inflação, ausência de capital adequado, estabilidade política e estrutura social. Essa análise, porém, torna-se complexa em virtude da ausência de dados e estatísticas recentes.

A economia brasileira oferece, não obstante, bases para um estudo apoiado em medidas qualitativas. A perspectiva mais conveniente para um estudo dessa natureza é a comparação sugerida por BARTEls. ${ }^{1}$ Segundo êsse conceito, duas providências devem ser tomadas:

Alberto de Oliveira Lima Filho - Prcfessor-Assistente do Departamento de Mercadologia da Escola de Administração de Emprêsas de São Paulo, da Fundação Getúlio Vargas.

1) RoBert BARTELs, "Comparative Marketing - Wholesaling in Fifteen Countries", Homewood, Ilinóis, Richard D. Irwin, Inc., 1963. 
- ressaltar os contrastes existentes nas práticas adotadas em dois mercados de serviços escolhidos a priori;

- analisar e prever as tendências em têrmos de fôrças econômicas e condições sociais.

Tomando por base uma classificação de serviços, descreveremos e compararemos os serviços existentes no Brasil e nos Estados Unidos da América. Atentaremos, a seguir, para o papel da mercadização no desenvolvimento econômico e, em conseqüência, na estrutura do composto de serviços existente no Brasil.

\section{EXPOSIÇÃO DE CONCEITOS}

Esclarecer os conceitos sôbre os quais a discussão será baseada torna-se necessário; portanto, antes de mais nada, conceituemos o que vêm a ser:

a) serviços em geral;

b) serviços que acompanham produtos;

c) produção terciária; e

d) mercadização comparada.

1. Serviços em geral — São atividades, benefícios, ou satisfações de desejos, que se oferecem a venda. Exemplos: diversões, serviços de hotel e restaurante, serviços elétricos, transportes, créditos, informações, consertos ou serviços de manutenção.

Para os fins dêste artigo, entretanto, uma subclassificação do mercado de serviços deve ser introduzida:

- serviços executados por pessoas e que, portanto, requerem apenas uma pequena aplicação de capital fixo para a sua realização;

- serviços cuja execução é feita mediante uso combinado de fôrça de trabalho e equipamento e que, portanto, requerem uma quantidade razoável de investimento; 
- serviços que exigem o uso intensivo de automatização e que, em conseqüência, demandam grandes investimentos em capital fixo.

Como será discutido adiante, o estágio de desenvolvimento econômico de um país e sua acumulação de capital influem no composto de serviços oferecidos ao mercado.

2. Serviços que acompanham produtos - São os serviços vendidos ou oferecidos em conexão com a venda ou oferta de mercadorias, produtos ou bens.

Êsses serviços aparecem como um ajustamento do produtor ou do comerciante às mudanças do ambiente competitivo, uma vez que o avanço das técnicas de produção, as informações do mercado, a competição de preços e a mobilidade do consumidor tornam as vendas e a mercadização uma tarefa mais difícil e complexa.

Nas economias em desenvolvimento, onde a competição não é intensa, os serviços oferecidos com produtos não representam mais do que um recurso, tática ou técnica de venda e não têm ainda papel decisivo no processo de mer cadização.

Isso, entretanto, não quer dizer que êsses serviços não existam; êles são oferecidos, mas apenas dentro de limites muito precários e por períodos quase irrisórios de três ou quatro meses. Em outras circunstâncias -- como, por exemplo, na indústria automobilística, em que a garantia é de seis meses - nota-se que os serviços e a assistência técnica prestada por alguns agentes são precários, e representam mais um trunfo de venda para o comerciante do que uma satisfação adicional de compra para o consumidor. Há algumas exceções no que diz respeito a certos produtos como refrigeradores e máquinas de costura, mas elas não invalidam a hipótese.

A inflação, por seu lado, também introduz restrições à oferta conjunta de produtos e serviços, uma vez que as taxas de salários, tornando-se obsoletas em seis ou doze meses, impossibilitam o oferecimento de serviços de qualidade quando o custo dêstes é incluído no preço de venda. 
3. Produção terciária - Estágio terciário de produção, nivel terciário ou indústria terciária é o estágio de desenvolvimento econômico que ressalta ou enfatiza comércio e transporte, finanças e comunicações, construções e obras públicas, atividades profissionais, pessoais e governamen. tais. Como essas atividades são, em sua maioria, serviços, uma economia em nível terciário experimenta uma parcela crescente de gastos no setor de serviços. ${ }^{2}$ Hollander assevera que nessas condições há um aumento sensível nos gastos com bens de luxo. ${ }^{3}$

Entre o estágio secundário e o terciário de produção há um período de transição bastante significativo. Mais ainda, há certos tipos de serviços que, embora pertençam ao nível secundário de produção, permanecem no terceiro estágio, ao passo que outros serviços sòmente são encontrados no estágio terciário. As diferenças e semelhanças demonstram que é impossivel estabelecer uma linha divisória entre dois estágios e que outras variáveis do problema da mercadização de serviços adiante examinadas também devem ser estudadas.

4. Mercadização comparada - E a interpretação da mercadização como atividade social e como parte componente das instituições econômicas de uma sociedade; é a explanação da estrutura e da prática da mercadização em função dos objetivos no mercado, do fluxo de atividades e das atitudes sociais. ${ }^{4}$

Analisando-se o problema sob êsse aspecto, será fácil estabelecer parâmetros e modelos para explicar o mercado de serviços no seu estágio atual no Brasil. As atitudes sociais, por exemplo, of erecem excelente pano-de-fundo para a discussão, uma vez que os serviços são julgados pelo povo brasileiro sob aspectos completamente diferentes dos considerados pelo norte-americano.

2) William REgAN, "The Service Revolution", Journal of Marketing, volume $27, \mathrm{n}^{\circ} 3$, julho de 1963 , pág. 60 .

3) Stanley HollaNDER, "Retailing: Cau:e or Effect" (mimeograph-$-M S U$ ).

4) ROBERT Bartels, op. cit., pág. 286. 
No Brasil os serviços são concebidos como um agrupamento de vantagens econômicas desfrutável sòmente pelas classes média e alta da população e oferecido apenas como um recurso de venda de serviços ineficientemente prestados pelas companhias de utilidade pública e executados por pessoas pertencentes às classes sociais mais baixas, trabalhadores semi-especializados e técnicos independentes.

Em nosso País os motivos que criam a procura e a oferta de serviços são bastante peculiares ao ambiente brasileiro. As nossas classes média e alta não sabem como executar pequenos reparos domésticos; servem-se para isso do encanador ou eletricista mais próximo. Os jardins das casas brasileiras são cultivados por jardineiros contratados por dia, e não, como nos Estados Unidos da América, pelos próprios membros da família.

É conhecido como traço caraterístico de nossa sociedade que os homens da casa nas famílias de classe alta ou média, ao contrário dos estadunidenses, não possuem as chamadas "habilidades manuais" - são homens de "punhos de renda". Êsse fato se explica pelo custo relativamente baixo da mão-de-obra que presta serviços no mercado brasileiro. Por outro lado, històricamente, êsses indivíduos não foram expostos ao aprendizado dessas tarefas.

No que tange à oferta conjunta de produtos e serviços, esta ainda não encontrou grande expansão porque lhe falta a "comercialização" adequada ao atendimento da demanda.

Há poucos meses atrás o consumidor brasileiro estava mais preocupado com adquirir bens para garantir o seu preço do que com procurar satisfação adicional nos serviços eventtualmente oferecidos pelos vendedores. Atualmente, entretanto, considerando-se a tendência futura da economia brasileira, podem-se prever modificações substanciais no comportamento do consumidor, no que diz respeito a serviços. 
Como já dissemos, uma das limitações da análise do nosso mercado de serviços é a ausência de dados estatísticos capazes de caraterizar, com a linguagem clara dos números, as posições tomadas durante a análise e, ao mesmo tempo, fornecer elementos mais significativos para a inferência de conclusões.

Entretanto, com base na classificação de PARKER" e classificando-se os serviços quanto ao nível de investimento necessário, é possível atingir razoável grau de precisão no que tange ao fator comparativo. Comparam-se os serviços enumerados por PARKer com os existentes no mercado brasileiro, interpretando-se da seguinte maneira os sinais da primeira coluna do Quadro 1:

A - Serviços menos usados no Brasil do que nos EUA.

AA - Serviços cujo grau de utilização no Brasil pode ser comparado com o dos EUA.

AAA - Serviços usados mais intensamente no Brasil do que nos EUA.

Por seu turno, a classificação concernente ao grau de investimento necessário à existência do serviço terá as seguintes caraterísticas (veja a segunda coluna do Quadro 1):

B - Serviços cuja execução exige uso intensivo de mão-de-obra e nenhum (ou pouco) investimento de capital.

$\mathrm{BB}$ - Serviços cuja execução requer uso de mão-de-obra combinado com investimento relativamente baixo.

BBB - Serviço cuja execução requer pouca utilização de mão-de-obra e alto grau de investimento.

5) Donald PARKer, The Marketing of Consumer Services, Universidede de Washington, pág. 25. 
Para os efeitos desta análise foram eliminados da classificação alguns serviços que existem apenas no mercado brasileiro ou, inversamente, só são encontrados nos EUA.

QUadro 1: Principais Serviços em que o Consumidor Aplica sua Renda

$\begin{array}{ccc}\text { Tipo de Serviço } & \text { Grau } & \text { Investimento } \\ & \text { Comparativo } & \text { Necessário } \\ \text { de Uso } & \text { de Capital }\end{array}$

I. SERVIÇOS DOMICILIARES
A) Utilidades públicas
B) Reparo de equipamento
C) Aluguel de equipamento
D) Reparo e manutenção da casa
E) Limpeza e serviços domésticos
F) Jardinagem
G) Mudanças e guarda-móveis
H) Limpeza de tapêtes e cortinas
I) Serviços de decoraçáo
J) Dedetização

$\begin{array}{rr}\text { A } & \text { BBB } \\ \text { AAA } & \text { B } \\ \text { A } & \text { BBB } \\ \text { AAA } & \text { B } \\ \text { AAA } & \text { B } \\ \text { AAA } & \text { B } \\ \mathbf{A} & \text { BBB } \\ \mathbf{A} & \text { BB } \\ \mathbf{A} & \mathbf{B} \\ \mathbf{A} & \text { BB }\end{array}$

II. MORADIA
A) Aluguel
B) Administraçãc predial

AAA

BBB

AA

EBB

III. SAÚDE
A) Diagnóstico, medicação e receituário
B) Cirurgia
C) Osteopatia
D) Oftalmologia
E) Psiquiatria
F) Odontologia
G) Enfermagem
H) Hospitalização
I) Enfermagem doméstica
J) Curativos

$\begin{array}{lr}\text { A } & \text { EB } \\ \text { A } & \text { BBB } \\ \text { A } & \text { EB } \\ \text { A } & \text { EB } \\ \text { A } & \text { BB } \\ \text { A } & \text { EB } \\ \text { A } & \text { B } \\ \text { A } & \text { BBB } \\ \text { A } & \text { B } \\ \text { A } & \text { B }\end{array}$

IV. TRANSPORTES E COMUNICAÇÕES
A) Transporte Particular
1. Atendimento, consêrto e guincho
2. Lavagem e polimento

$\begin{array}{rr}\text { A } & \text { BBB } \\ \text { AAA } & \text { BB } \\ \text { AAA } & \text { BB } \\ \text { A } & \text { BBB } \\ \text { A } & \text { BBB } \\ \text { A } & \text { BBB } \\ \text { A } & \text { BBB } \\ \text { A } & \text { BBB } \\ & \\ \text { A } & \text { BB } \\ \text { A } & \text { BB } \\ \text { A } & \text { BB }\end{array}$




$\begin{array}{ccc}\text { Tipo de Serviço } & \text { Grau } & \text { Investimerto } \\ & \text { Comparativo } & \text { Necessário } \\ \text { de Uso } & \text { Capital }\end{array}$

V. ATIVIDADES FINANCEIRAS
A) Empréstimos
B) Serviças de bancos
C) Corretores de ações
D) Crédito no varejo (ac consumidor)
E) Consultoria de investimentos
F) Consultoria fiscal
G) Heranças
H) Reméssa de valôres

$\begin{array}{rr}\mathbf{A} & \text { BBB } \\ \mathbf{A} & \mathbf{B B B} \\ \mathbf{A} & \mathbf{B B} \\ \mathbf{A A A} & \mathbf{B B B} \\ \mathbf{A} & \text { BB } \\ \mathbf{A} & \text { BB } \\ \mathbf{A} & \text { BB } \\ \mathbf{A} & \text { BB }\end{array}$

\section{SEGURO}
A) Pessoal
B) Da propriedade

A

BBB

A

BBB

VII. SERVIÇOS PESSOAIS
A) Vestuário
B) 1. Limpeza
2. Passamento a ferro
3. Tingidura
4. Lavagem
5. Reformas
6. Consertos
7. Estufa
8. Alugue1
C) Cuidado pessoal
1. Barbearia
2. Instituto de beleza
3. Sauna, duchas etc.
4. Contrôle de pêso e modelagem

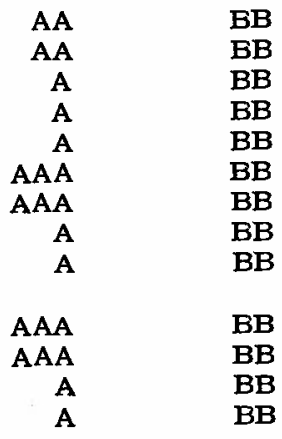

VIII. RECREAÇÄO

A) Sem participação

B) Com participação

$\begin{array}{ll}\text { AA } & \text { BBB } \\ \text { AA } & \text { BBB }\end{array}$

IX. EDUCAÇÃO
A) Pública (sem taxas no Brasil)
B) Particular

$\begin{array}{ll}\text { A } & \text { BBB } \\ \text { A } & \text { BBB }\end{array}$

X. VÁRIOS
A) Religião
B) Previdência social
C) Asscciação sindical (compulsória)
D) Fotografia
E) Serviço funerário
F) Serviço de veterinária
G) Assistência jurídica
H) Agência de empregos
I) Associação profissional
J) Arquitetura

$\begin{array}{rr}\text { A } & \text { BB } \\ \mathbf{A} & \mathbf{B B B} \\ \mathbf{A A A} & \mathbf{B B} \\ \mathbf{A} & \mathbf{B B} \\ \mathbf{A} & \mathbf{B B} \\ \mathbf{A} & \mathbf{B B} \\ \mathbf{A} & \mathbf{B} \\ \mathbf{A} & \mathbf{E B} \\ \mathbf{A} & \mathbf{B B} \\ \mathbf{A} & \mathbf{B B}\end{array}$

Fonte: Donald D. PARKer, The Marketing of Consumer Services, Seattle: Universidade de Washington, 1960 (adaptação). 
Embora a classificação estabelecida no Quadro 1 ' não permita uma avaliação quantitativa dos serviços existentes no Brasil, melhor classificação pode ser obtida relacionando-se o grau de utilização comparativa de serviços nas duas economias com a quantidade de investimento necessária à existência de tais serviços.

Fazendo-se uma classificação cruzada do grau de utilização com a necessidade de investimento, pode-se criar u'a matriz de nove células que mostre os principais tipos de serviços existentes no Brasil, classificados em função do grau de utilização e do de investimento. Cada uma das nove células da matriz tem as seguintes caraterísticas:

1) AB - Menor grau de utilização no Brasil do que nos EUA. Sem necessidade de investimento de capital.

2) $\mathrm{AAB}$ - Igual grau de utilização nos dois países. Sem necessidade de investimento de capital.

3) AAAB - Maior grau de utilização no Brasil do que nos EUA. Sem necessidade de investimento de capital.

4) $\mathrm{ABB}$ - Menor grau de utilização no Brasil do que nos EUA. Necessidade de investimento pequeno ou médio de capital.

5) AABB - Igual grau de utilização nos dois países. Necessidade de investimento pequeno ou médio de capital.

6) AAABB - Maior grau de utilização no Brasil do que nos EUA. Necessidade de investimento pequeno ou médio de capital.

7) ABBB - Menor grau de utilização no Brasil do que nos EUA. Necessidade de investimento elevado de capital.

8) AABBB - Igual grau de utilização nos dois países. Necessidade de investimento elevado de capital.

9) AAABBB - Maior grau de utilização no Brașil do que nos EUA. Necessidade de investimento elevado de capital. 
O Quadro 2 mostra a classificação cruzada que foi obtida pela matriz.

QUADRo 2: Utilização Comparativa de Serviços no Brasil e nos EUA/Nível de Investimento Necessário

(Classificação Cruzada)

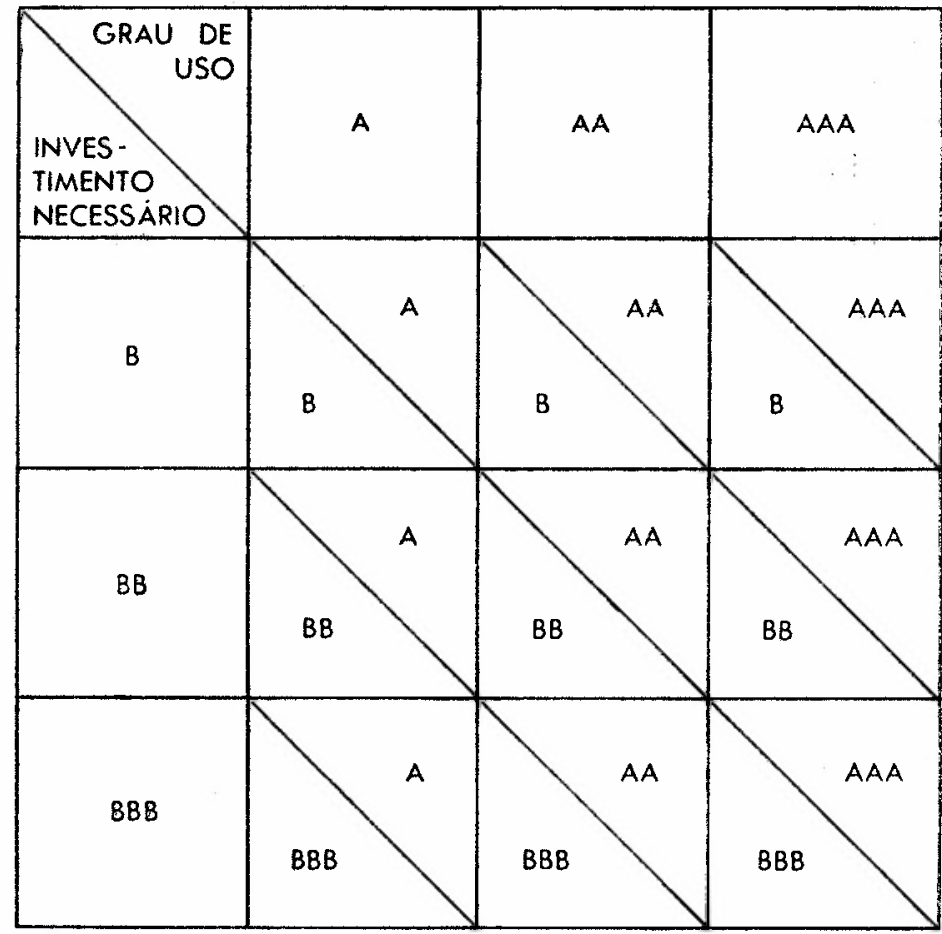

Nota: O inyestimento é considerado como a quantidade de capital fixo necessária para dar ao negócio condições de funcionamento.

Em prosseguimento da análise, foi elaborado o Quadro 3 para indicar a caraterística de cada uma das células determinadas pela construção do Quadro 2. 
Quadro 3: Utilização Comparativa de Serviços no Brasît

e ros EUA/Nivel de Investimento Necessário - Caraterísticas das Células (Classificação Cruzada)

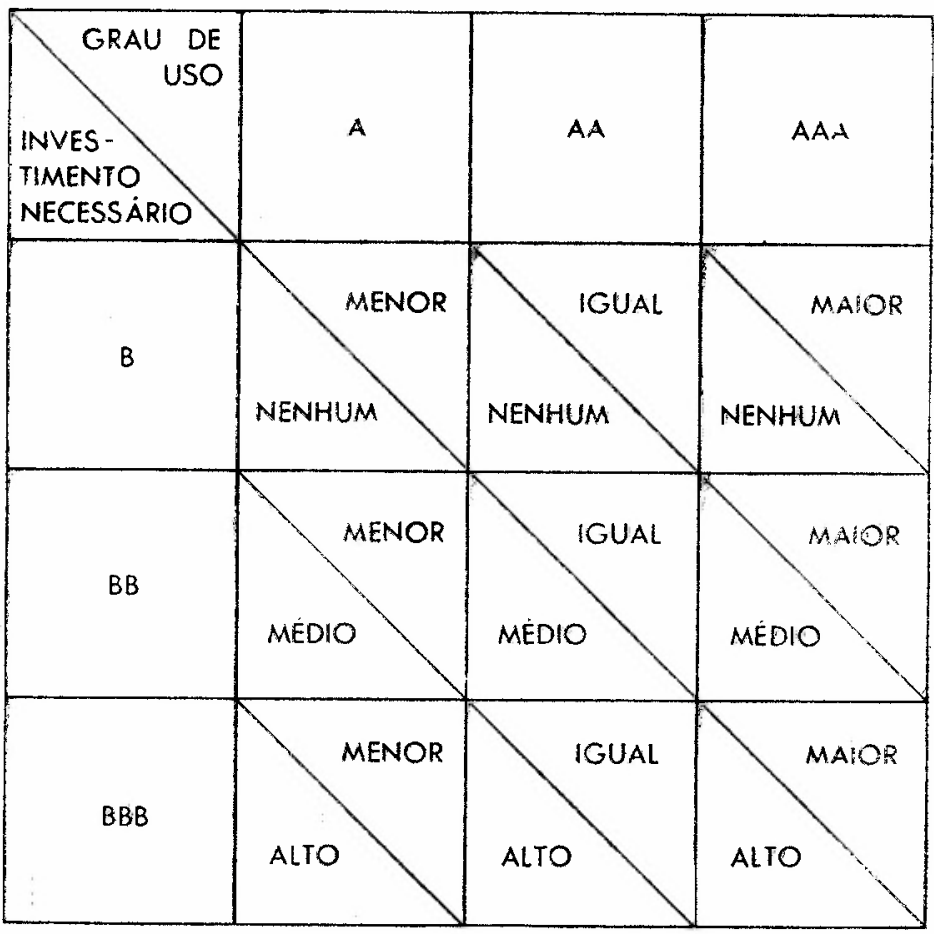

Finalmente, com o objetivo de apresentar uma interpretação mais significativa dos resultados encontrados pela aplicação das matrizes na presente análise, a freqüência de ocorrência em cada célula de classificação cruzada foi tabulada no Quadro 4. Além disso, as porcentagens relativas de cada uma das variáveis foram calculadas tendo-se em vista a apresentação de resultados padronizados. 
Quadro 4: Utilização Comparativa de Serviços no Brasil e nos EUA/Nível de Investimento Necessário - Fteqüências e Porcentagens (Classificação Cruzâda)

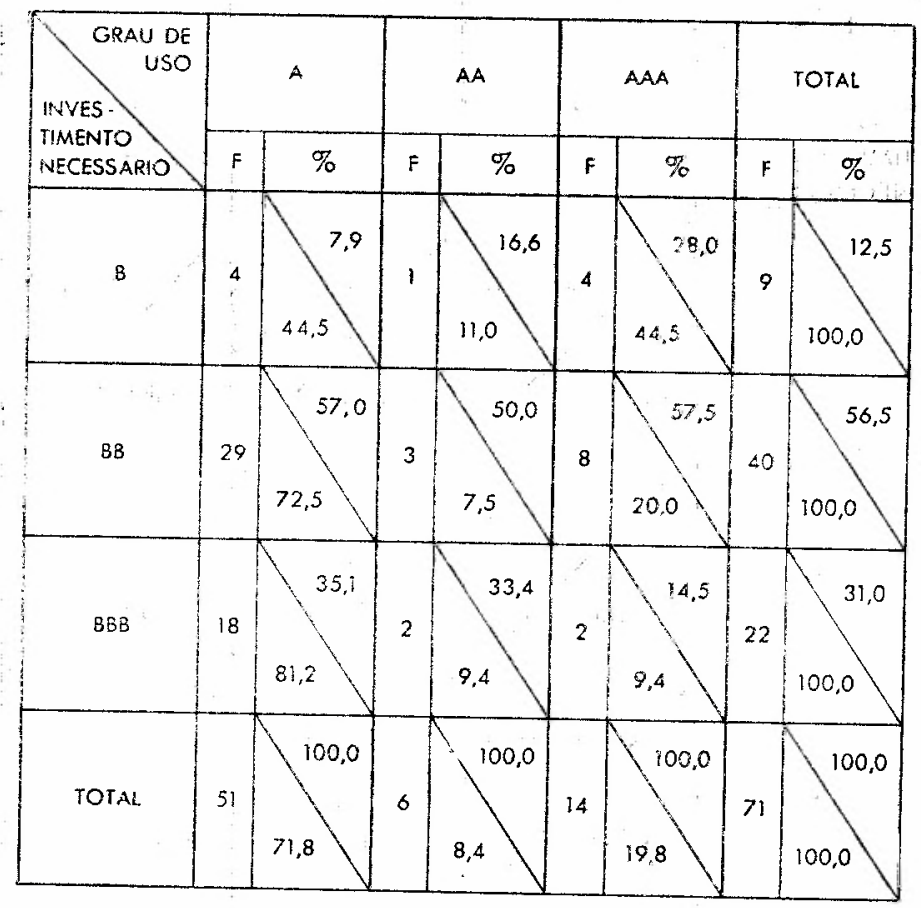

$V$ erifica-se pelo Quadro 4 que dentre os 71 serviços mencịnados por PARKER 51 (71,8\%) são menos utilizados na Brasil do que nos Estados Unidos da América, 6 $(8,4 \%)$ têm o mesmo grau de utilização e 14 (19,8\%) são mais utilizados pelo consumidor brasileiro. 
No que concerne ao investimento de capital relacionado com a execução de serviços, $49(69 \%)$ parecem necessitar de pequena ou nenhuma quantidade de investimento fixo. Por outro lado, sòmente $22(31 \%)$ dos serviços exigem investimentos elevados.

Dentre os serviços que requerem elevados investimentos $18(81,2 \%)$ têm baixo grau de utilização no Brasil: aluguéis de veículos, serviços financeiros, seguros e educação; representam $35,1 \%$ dos serviços menos utilizados no Brasil, comparativamente aos Estados Unidos da América.

Outro fato interessante é que 29 (57\%) dos serviços menos utilizados requerem pequeno ou médio investimento em capital fixo (célula $A B B$ ). Uma das razões para essa alta freqüência na célula poderia ser relacionada com a incapacidade do consumidor brasileiro para pagar serviços médicos ou dentários, por serem relativamente caros e pouco difundidos no meio social brasileiro.

Com relação ao capital investido, verifica-se que 4 (28\%) dos serviços utilizados em maior escala no Brasil são executados sem necessidade de investimento de capital (é o caso dos serviços de jardinagem, reparos e serviços domésticos em geral); 8 (57,5\%) necessitam pequeno ou médio investimento: são serviços oferecidos a preços relativamente baixos, por emprêsas pequenas, tais como restaurantes, institutos de beleza etc. .

De maneira geral, as seguintes conclusões podem ser tiradas da análise acima:

- O mercado de serviços no Brasil é proporcionalmente menor do que o dos Estados Unidos da América.

- A oferta restrita de serviços em alguns segmentos da classificação de PARKER pode ser correlacionada com a alta deficiência de capitais na economia do Brasil.

Há considerável utilização de serviços no Brasil quando o seu custo é baixo e quando não há necessidade de investimento em capital fixo. 
Nas partes seguintes dêste artigo desenvolveremos algumas conclusões relativas às possibilidades do mercado de serviços no Brasil, pela análise da hipótese dos autores Clatark e Fisher, dos estudos de Holton, em seu "Programa de Desenvolvimento Econômico de Pôrto Rico", e das proposições de THORELLI.

HIFÓTESE "CLARK—FISHER" — SUA APLICABILIDADE

Colin Clark e Allen Fisher consideram que a proliferação de serviços principia no momento em que os problemas de produção tenham sido solucionados. Nesse ponto de crescimento econômico de uma nação o conceito de sociedade abastada, proposto por GALBRAITH, e o de econcmia de abundância, indicado por ROBERT THEOBald, podem ser entendidos em tôda a sua magnitude. Nesse periodo mcdifica-se a relação entre tempo e esfôrço humano e entre capital e equipamento para a produção de bens e serviços que passam a não mais ser classificados, no sentido amplo da expressão, nas categorias primária ou secundária da produção."

A análise levada a efeito na parte anterior dêste trabalho sugere a mesma conclusão, uma vez que o país mais desenvolvido (EUA) apresenta maior utilização de serviços do que o país em desenvolvimento (Brasil). Nota-se, porém, que alguns tipos de serviços são oferecidos tanto em economias subdesenvolvidas, como em ambientes econômicos mais avançadcs. O que acontece, na realidade, é que êsse fenômeno se relaciona com um conjunto de variáveis relativamente amplo, no qual precisam ser considerados, entre outros, os seguintes fatôres: preço, investimento, custo do salário e poder de compra das classes média e alta.

De acôrdo com essa interpretação, notam-se a oferta e a procura de serviços que possam ser produzidos e distribuí-

6) Allen Fisher, Progress and the Change in Demand for Food - The Check of Progress and Security, Londres: MacMillan \& Company, 1935. 
dos em massa para um segmento relativamente grande da população. Por outro lado, o grau de automatização, condição necessária à oferta de serviços nas economias de abundância, não deve ser considerado como óbice à existência de serviços nas economias mais pobres. Depois de um estágio inicial, quando os salários começam a subir, os serviços começam a ser vagarosa, mas progressivamente, automatizados, vale dizer, há um crescente grau de investimento no mercado de serviços.

Dessa maneira, o chamado composto de serviços tenderá a ser diferente, em têrmos de quantidade, forma, qualidade etc., mas em sua essência alguns serviços ofertados no estágio terciário serão semelhantes aos encontrados nos mercados do estágio secundário da produção.

O Prof. Cundiff, da Universidade do Texas, explica êsse fenômeno relacionando-o com a estrutura de custos dos serviços nos diferentes estágios econômicos.

Portanto, as mudanças que ocorrem durante a fase de transição entre o estágio secundário e o terciário são relativamente lentas, e a prova disso está no fato de que a forma de oferta de muitos serviços permanece inalterada. Por exemplo: os postos de lavagem de automóveis que atualmente estão sendo instalados em São Paulo operam com muito maior proporção de mão-de-obra do que os existentes nos Estados Unidos da América. Os "boliches" brasileiros não têm reposição automática de garrafas, nem devolução automática de bolas aos jogadores.

Mais ainda, a transição no composto de serviços e o seu aumento estão sujeitos a certas fôrças e fatôres, tais como lugar (as diferenças espaciais mencionadas por BARTELS), costumes sociais, política e pressão do ambiente competitivo. Ilustração adequada dêsse fenômeno é o aparecimento de companhias de táxis no Brasil.

Enfim, a hipótese de Clark e Fisher pode ser aceita, mas com restrições quanto às caraterísticas do período de transição, as quais podem ser resumidas da seguinte forma: 
a) variações no composto de serviços relativamente lentas;

b) variação no grau de utilização dos fatôres de produção fôrça do trabalho versus equipamento.

ESTÁGIO TERCIÁRIO: EFEITOS SÔBRE O SISTEMA DE MERCADIZAÇÃO

O alcance completo do estágio terciário de produção depende da ação conjunta de vários fatôres.

As inovações podem ganhar mais aceitação nos países estrangeiros do que em seus locais de origem. Mas, também pode ocorrer o inverso. $\mathrm{Da}$ mesma maneira, pode-se afirmar que certos padrões no mercado de serviços se apresentam como barreiras à proliferação dos serviços em massa. Costumes e diferenças culturais podem afetar negativamente o esfôrço criador de técnicas novas; a inflação pode não permitir esforços administrativos no sentido de reduzir as margens e aumentar o volume de distribuição. Normas legais nem sempre reconhecem a necessidade da utilização extensiva de receitas e cuidados médicos. A ausência de contrôle, de um lado, contrabalançada, de outro, por contrôles excessivos no exercício de profissões de natureza ética, conduz a uma situação na qual não existe competição de preços nem tentativas de redução de custos.

Com relação aos serviços de distribuição de bens alimentícios, nota-se que os brasileiros, por mais de 50 anos, compraram em armazéns e feiras-livres, o que de certo modo explica a lentidão com que vêm sendo aceitos os serviços oferecidos por supermercados, tanto em relação aos produtos (limpeza, refrigeração, embalagem), como em relação ao ambiente (música, espaço, asseio). ${ }^{8}$

7) StANley Hollander, op. cit..

8) William KNOKE, "O Supermercado no Brasil e nos Estados Unidos", São Paulo: Revista de Administração de Emprêsas, Volume 3, N.o 9, घgôsto de 1963. 
O fato é que ainda não foi configurada pelo público e pelos empresários a importância da utilização de serviços; assim sendo, a demanda permanece estática no seu estágio potencial. Particularmente em algumas áreas - serviços de investimentos, máquinas operadas com moedas, reembôlso postal - pouco ou nada foi feito até aqui.

Empecilhos de ordem política e econômica não permitiram até agora a aplicação de grandes investimentos em ativos fixos, feito que favoreceria a expansão de serviços em nosso meio; a renda per capita ainda é baixa, mas está demonstrando tendências de crescimento, principalmente nas classes médias, que representarão no futuro o principal mercado, quantitativa e qualitativamente.

Nesse ponto da análise é necessário indagar se as tendências do mercado brasileiro de serviços se ajustam ao argumento de Holton, ou seja: é ou não possível estabelecer uma oferta substancial de serviços antes de a economia ter alcançado alto grau de desenvolvimento econômico?

Aos economistas preocupados com o desenvolvimento econômico das nações mais pobres, HoLton aconselha que envidem esforços mercadológicos apropriados ao aumento da of.erta de bens e serviços. Os estudos de HoLToN indicam que a mercadização de serviços pode promover o aumento da taxa de desenvolvimento e, ao mesmo tempo, aperfeiçoar o processo de mercadização. E admissível a aplicação dessa tese ao mercado brasileiro de serviços, mas com reservas: no Brasil, como vimos, certos tipos de serviços permanecem em ambos os estágios econômicos, ao passo que outros sòmente passam a proliferar quando se atinge alto padrão de abundância.

As diferenças espaciais mencionadas por BARTELs são igualmente relevantes, visto que as estatísticas de desenvolvimento não reconhecem a existência de áreas altamente desenvolvidas nos países em fase de crescimento.

9) EDWARD CUNDIFF, "Concepts in Comparative Retailing", Jcurnal of Marketing, Volume 29, janeiro de 1955, págs. 55 a 63. 
Como as teorias de Clark-Fisher e de Holton não intrcduzem essa variável, elas não são válidas para explicar o status quo do nosso mercado de serviços.

\section{FATÔRES ECONOMMICOS E POLÍTICOS - SUA INTERAÇÃO}

Segundo ThORELlI, Política e Economia estão intrìnsecamente correlacionadas. ${ }^{10}$ Uma vez que êsse conceito é aplicável ao composto de serviços dos países em desenvolvimento, as razões para o baixo padrão de serviços oferecidos no Brasil pelas companhias de utilidade pública são fàcilmente compreensíveis. Considerando-se que a acumulação de capitais é insuficiente e que a instabilidade polí. tica brasileira restringe a aplicação de capitais estrangeiros no País, os serviços de utilidade pública não aumentam na mesma proporção do crescimento populacional, nem em função dos aumentos de renda per capita. A baixa eficiência existente no mercado de serviços de interêsse público é correlacionada com fatôres econômicos que, por sua vez, são afetados por determinantes políticos.

THORELli enunciou duas proposições que podem explicar a situação delineada acima:

a) sob um sistema político democrático, o desenvolvimento econômico é possível quando existe certo grau de liberdade na escolha dos bens a consumir, sendo êsses bens de tal modo variados que essa liberdade de escolha seja significativa;

b) o desenvolvimento econômico é mais uma questão de atitudes do que um problema de capitais, equipamentos ou habilidades educacionais. ${ }^{11}$

É claro, pois, que as atitudes governamentais, as restrições ao investimento estrangeiro e a burocracia representam no Brasil barreiras ao desenvolvimento dos mercados de

10) Hans Thorelli, Political Science and Marketing - Theory in Marketing, Homewood, Ilinóis: American Marketing Association, Richard D. Irwin, Inc., 2. a série, 1964, pág. 130.

11) Idem, ibidem, pág. 131. 
serviços. A procura potencial dêsses serviços existe em nosso País, mas as condições que possibilitariam a sua oferta só serão desenvolvidas quando evoluir a mentalidade política do povo brasileiro.

Vejamos agora a terceira proposição de THORELLI:

c) nenhum veículo é mais poderoso do que a filosofia mercadológica contemporânea para modificar as atitudes no sentido de conduzi-las à melhoria dos padrões de vida nas sociedades democráticas. ${ }^{12}$

A análise dessas três proposições estabelece uma ligação entre a hipótese de ClARK e Fisher e a tese de Holton, segundo a qual o estágio terciário de produção pode ter lugar numa economia subdesenvolvida ou em desenvolvimento. Essas três proposições parecem ajustar-se melhor à situação brasileira.

O sistema de mercadização irá mudar e adaptar-se às ten: dências econômicas; certamente êsse mecanismo não será inconseqüente. Ao contrário, após as sociedades em desenvolvimento passarem por uma fase de adaptação ao aparecimento de indústrias e vias de distribuição orientadas para o consumidor, haverá novas atitudes resultantes da aceitação da mudança e, como conseqüência, um acréscimo na mobilidade social. ${ }^{13}$

RESUMO E CONCLUSŌES

Tomando-se dois ambientes econômicos diferentes, é possível analisar as tendências e a estrutura da mercadização de serviços com certo grau de precisão, apesar da ausência de dados estatísticos. Os resultados da análise são comparáveis qualitativamente, mas não sob o aspecto quantitativo.

12) Idem, ibidem, pág. 131.

13) ERNEST Dichter, The World Customer, Bóston, Mass.: Harvard Business Review, Volume 40, n. 4, julho/agôsto de 1962, págs. 113 a 121. 
Estudos, como a conhecida hipótese de Clark e Fisher e o "Programa de Desenvolvimento Econômico de Pôrto Rico" realizado por HolToN apresentam base de referência para uma análise dêsse tipc; êsses modelos, entretanto. não mencionam o perícdo de transição, que é realmente crítico.

Os estudos de THORELLI - que adotam a perspectiva do problema da mercadização de serviços sob o aspecto político-científico - oferecem finalmente ótimo suporte para a análise.

O composto de serviços deve ser considerado como fator extremamente dinâmico, e não como uma porção estática do sistema de mercadização em ambiente econômico.

A capacidade para realizar investimentos de capital num país em desenvolvimento representa fator de extrema importância para o aumento da oferta de serviços. As taxas de salário e suas relações com o custo e o poder de compra são de enorme relevância quando a existência de certos tipos de serviços não requer investimento. E evidente que êsses fatôres representam as variáveis da função de procura.

O método de matrizes e a análise comparativa clareiam a percepção do problema e possibilitam ao analista compreensão melhor dos conceitos de serviços em geral, serviços que acompanham produtos, produção terciária e mercadização comparada.

A utilização de serviços pode ser relacionada com o desenvolvimento econômico, se se entender que os serviços devam ser produzidos, distribuídos e vendidos em massa. Alguns serviços, entretanto, são encontrados em ambos os estágios econômicos, o que torna complexa, mas muito interessante, a análise da sua fase de transição.

Cabe ao administrador mercadológico tomar conhecimento dêsses fenômenos a fim de capitalizá-los a favor de seu esfôrço de mercadização. 
1. RoBert Bartels, Comparative Marketing - Wholesaling in Fifteen Countries, Homewood, Ilinóis, Richard Irwin, Inc., 1963.

2. EdWARD CUNDIFF, "Concepts in Comparative Retailing", Journal of Marketing, Volume 29, janeiro 1965, pág 55-63.

3. ERnest Dichter, The World Customer, Bóstcn, Mass.: Harvard Business Review, Volume 40, n. ${ }^{\circ} 4$, julho/agôsto de 1962, págs. 113-121.

4. Allen Fisher, Progress and the Change in Demand for Food - The Check of Progress and Security, Londres: Macmillan \& Company, 1935 (apud Explorations in Retailing, de Hollander).

5. Stanley Hollander, Explorations in Retailing, East Lansing, Michigan: MSU Business Studies, 1959.

6. Stanley Hollander, "Retalling: Cause ot Effect" (mimeograph-MSU).

7. William KNOKE, "O Supermercado no Brasil e nos Estados Unidos", São Paulo: Revista de Administração de Emprêsas, Volume 3, N. ${ }^{\circ}$, agôsto de 1963. 